\title{
WHERE'S THE REEF?: A CRITICAL REEVALUATION OF THE ROLE OF FRAMEWORK
}

\author{
HUBBARD, Dennis K., West Indies Laboratory, 5046 Cotton Valley, St. Croix, USVI, \\ $00820-4519$
}

Despite suggestions to the contrary by Norman Newell, in 1971, the presence of inplace, interlocking framework remains primary among the list of criteria used to recognize "true reefs" in the rock record. This is a logical outgrowth of observations made in modern systems, emphasizing 1) high carbonate-production rates of modern corals, 2) their commonly upright and interlocking architecture, and 3) the abundance and diversity of closely packed organisms on the surface of many modern reefs.

Applying a framework-dominated model to ancient reefs, however, has led to repeated frustration and the assumption that the problem is by and large related to the changing nature of reefs through time. Our present attempt to apply uniformitarianism to modern reefs and their ancient counterparts was perhaps best summarized by $\mathrm{H}$. A. Lowenstam, "The present is the key to the Pleistocene... perhaps".

A growing data base from cores through modern reefs implies that much of the problem is related to real differences between what we think constitutes the interior of modern reefs and what is really there. Recognizable coral generally constitutes less than $30 \%$ of the reef fabric, based on examination of over 50 cores from a variety of reef types throughout the eastern Caribbean region. Volumetrically, loose sediment and void space comprise a significantly higher portion of the reef interior. Furthermore, obviously inplace and interlocking "framework" is conspicuously absent. Branching Acropora palmata is invariably found in a variety of orientations, implying largely detrital emplacement rather than the preservation of intact and undisturbed colonies. Head corals are generally separated by intervals of detritus or open cavities, rather than sitting atop older colonies. Where rigidity of the reef fabric can be observed, it is almost always a function of secondary encrustation by coralline algae and/or post-depositional marine cementation.

The patterns seen in cores are supported by previous budget calculations of carbonate cycling in modern reefs around St. Croix. Bioerosion reduces original carbonate material to sediment, leaving recognizable coral to represent only a small part of the total reef volume. While still a significant component of the total reef fabric, few of the recognizable corals are bound together, and it is difficult to clearly demonstrate that the samples were recovered from life position (although some probably were). At Salt River, recovery was very low, and corals have been demonstrably moved from their original sites of growth.

Effective modeling of ancient reefs must take into account the importance of secondary processes that reduce and redistribute the original carbonate material produced by corals. Combined with physical reworking, cementation and encrustation, these destructive processes result in a deposit that resembles more a pile of reef debris than the coherent assemblage of in-place, interlocking framework usually conjured up to represent the modern-reef interior. While still of great importance, constructional processes that are so evident on the reef surface must be viewed within the context of other physical, chemical and biological processes that are reflected in the growing body of core data from modern reefs in the western Atlantic and throughout the world. 